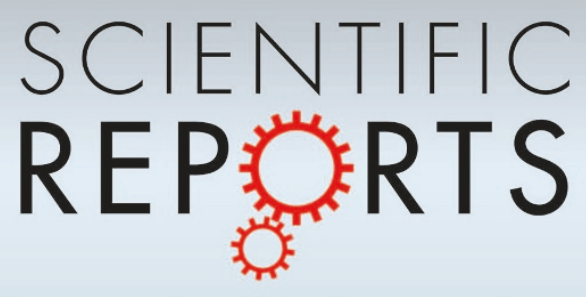

OPEN

SUBJECT AREAS:

PHYSICAL

OCEANOGRAPHY

ATMOSPHERIC DYNAMICS

CLIMATE AND EARTH SYSTEM MODELLING

Received

30 April 2014

Accepted

24 July 2014

Published

12 August 2014

Correspondence and requests for materials should be addressed to B.N. (Benjamin.Ng@ csiro.au)

\section{The role of the SST-thermocline} relationship in Indian Ocean Dipole skewness and its response to global warming

\author{
Benjamin $\mathrm{Ng}^{1,2}$, Wenju Cai' \& Kevin Walsh ${ }^{2}$
}

${ }^{1}$ CSIRO Marine and Atmospheric Research, Aspendale, Victoria, Australia, ${ }^{2}$ School of Earth Sciences, University of Melbourne, Parkville, Victoria, Australia.

A positive Indian Ocean Dipole (IOD) tends to have stronger cold sea surface temperature anomalies (SSTAs) over the eastern Indian Ocean with greater impacts than warm SSTAs that occur during its negative phase. Two feedbacks have been suggested as the cause of positive IOD skewness, a positive Bjerknes feedback and a negative SST-cloud-radiation (SCR) feedback, but their relative importance is debated. Using inter-model statistics, we show that the most important process for IOD skewness is an asymmetry in the thermocline feedback, whereby SSTAs respond to thermocline depth anomalies more strongly during the positive phase than negative phase. This asymmetric thermocline feedback drives IOD skewness despite positive IODs receiving greater damping from the SCR feedback. In response to global warming, although the thermocline feedback strengthens, its asymmetry between positive and negative IODs weakens. This behaviour change explains the reduction in IOD skewness that many models display under global warming.

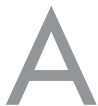

n IOD event is an anomaly pattern of SST variability that occurs on interannual time scales over the tropical Indian Ocean $(\mathrm{IO})^{1,2}$. The IOD is positively skewed with its positive phase tending to have stronger cold SSTAs off Sumatra-Java than warm SSTAs during its negative phase ${ }^{3-5}$. These positive events are associated with anomalously cool SSTs over the eastern pole of the IOD (IODE; $90^{\circ} \mathrm{E}-110^{\circ} \mathrm{E}, 10^{\circ} \mathrm{S}-\mathrm{Eq}$.) and warm SSTAs to the west, often causing droughts in Indonesia and Australia, as well as flooding in parts of India and East Africa ${ }^{6-8}$. Furthermore, positive IODs (pIODs) precondition southeast Australia for major bushfires and the associated flooding can worsen malaria outbreaks in East Africa ${ }^{9,10}$. Due to these severe impacts, it is important to understand what causes the positive skewness of the IOD, and how these causes will respond to increasing greenhouse gases. Many models from phase 5 of the Coupled Model Intercomparison Project (CMIP5) show that in response to global warming, the positive skewness of the IOD weakens ${ }^{11,12}$.

The negative SST-cloud-radiation (SCR) feedback is one of two feedbacks that have been proposed as the main source of IOD skewness. This feedback is associated with the cloud cover response to SST, the incoming shortwave radiation (SWR) response to cloud, and the incoming SWR response to SST. During pIOD events, the cold IODE SSTAs reduce local cloud cover, allowing greater incoming SWR which acts to warm the cold SSTAs. It is suggested that this feedback is the main cause of IOD skewness through a breakdown of the feedback, which leads to greater damping of nIODs than PIODs $^{3,4,13}$. However, there is some debate ${ }^{14-16}$ regarding the SCR feedback's role in generating positive IOD skewness and the data used in previous analysis ${ }^{13}$ may contain biases ${ }^{5}$. For instance, the Simple Ocean Data Assimilation (SODA) 2.0.2 product $^{17}$ has a cold bias when compared with Hadley Centre Global Sea Ice and SST (HadISST) reanalysis ${ }^{5,18}$. This may mean that the thermocline is too shallow in SODA2.0.2 and thus, the asymmetry of the subsurface temperature-thermocline relationship would not be captured. The response of the SCR feedback to global warming and its role in weakening IOD skewness is also not well known.

The second feedback that has been proposed as the cause of skewness is a positive Bjerknes feedback involving the SST response to the thermocline (ZT), the wind response to SST, and the thermocline response to wind. Cold IODE SSTAs (i.e., pIODs) lead to a zonal temperature gradient which drives an easterly wind anomaly. This wind anomaly shoals the thermocline in the east, reinforcing the cold SSTAs by bringing cool deep water closer to the surface. The Bjerknes feedback contributes to IOD skewness by reinforcing pIODs more strongly than nIODs ${ }^{12,19}$. 


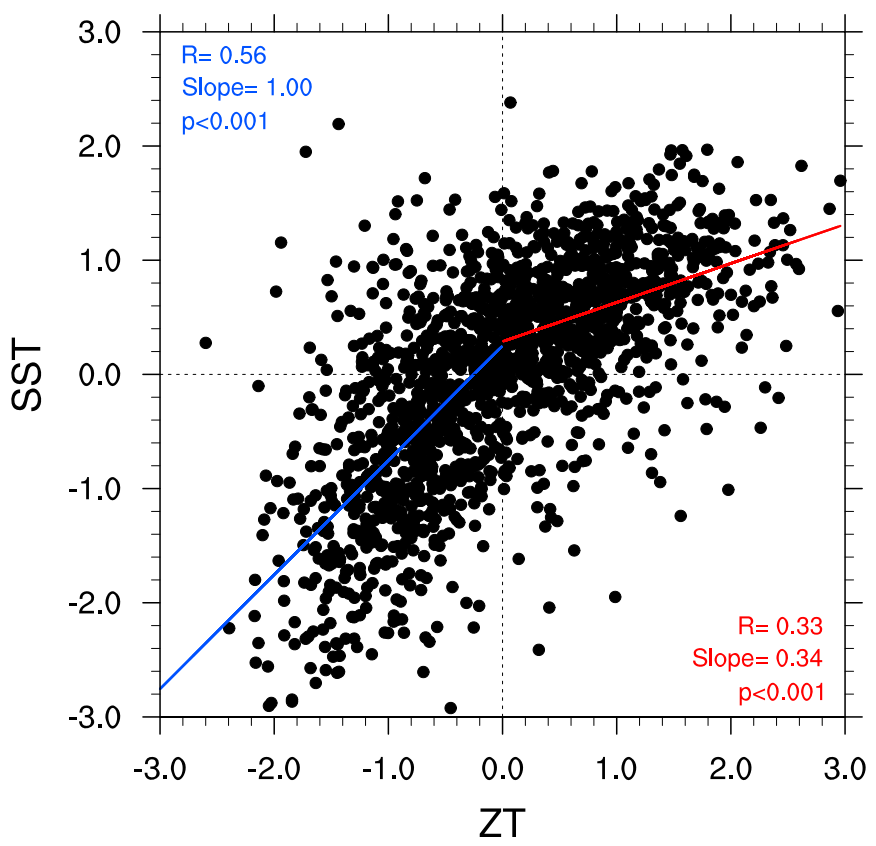

Figure $1 \mid$ Relationship between SST and thermocline depth (ZT). Austral spring (SON) SSTAs versus thermocline depth anomalies during the historical period (1911-2005). SST and ZT are both averaged over the IODE region $\left(90^{\circ} \mathrm{E}-110^{\circ} \mathrm{E}, 10^{\circ} \mathrm{S}\right.$-Eq.) and normalized by their respective standard deviations. Linear regression and correlation using positive only (red regression line) or negative only (blue regression line) samples have been calculated over the normalized data with the correlation, slope, and $p$ value indicated. All plots were generated in NCL.

This contribution to IOD asymmetry is primarily caused by the SST response to the thermocline (i.e., a thermocline feedback) and this has been shown in observations ${ }^{14,15}$. As seen in Fig. 1, models are able to simulate the asymmetry of this thermocline feedback. In this ensemble of 19 models, the SST response to a shoaling thermocline (blue regression line) is almost three times stronger than the response to a deepening thermocline (red regression line). It is hypothesized that under global warming, the skewness of the IOD decreases due to a shoaling thermocline and weaker warming in the eastern $\mathrm{IO}^{11,12}$. Although previous studies have hypothesized the role of the thermocline in causing IOD skewness and its response to climate change, inter-model statistics have not been examined to understand its asymmetry or role in generating skewness. This is the focus of our present study.

\section{Results}

Cause of skewness in CMIP5 models. Using 19 CMIP5 models, the source of IODE SST skewness is examined with a focus on the two main feedbacks that have been proposed as the primary cause. If the SCR feedback is the main cause of IOD skewness then the precipitation response to SSTAs should be weak during pIODs, but strong during nIODs. However, a number of the models (7) do not simulate this response and for models that do show the correct sign, the asymmetry between positive and negative IODs is weak. Figure 2a plots historical IODE SST skewness against the slope difference between positive and negative IODs (i.e., the linear regression coefficient for pIODs minus the linear regression coefficient for nIODs). A negative slope difference means that the rainfall response to warm IODE SSTs (i.e., nIODs) is stronger than the response to cold IODE SSTs (i.e., pIODs), which is how the SCR feedback generates IODE SST skewness ${ }^{13}$. If the SCR feedback were the main cause of IOD asymmetry in the models, then a negative slope difference on the $\mathrm{x}$-axis should be associated with more negative IODE SST skewness on the y-axis. However, Fig. 2a shows that when the slope difference is negative (i.e., the slope for warm IODE SSTAs is greater than the slope for cool SSTAs), IODE SST skewness tends to be weaker. This is opposite to what is expected, although the correlation is not statistically significant at the 95\% confidence level using Student's $t$-test (two-tailed).

In RCP8.5 the relationship between IODE SST skewness and slope difference strengthens (Fig. 2b), but it actually further contradicts what is expected for the SCR feedback to be the primary cause. This is because the results in Figs. $2 \mathrm{a}$ and $2 \mathrm{~b}$ suggest that models that have greater damping (i.e., when the slope difference is positive) tend to have more negative IODE SST skewness. This means that the negative SST skewness is being generated despite greater damping during pIOD events and that the SCR feedback does not breakdown. As such, our inter-model statistics suggest that the SCR feedback is not the main source of IOD asymmetry in the models.

There are many possible reasons for the behaviour of the SCR feedback. One possible explanation is that it is a result of a stronger thermocline feedback. As the thermocline feedback reinforces pIODs more strongly than nIODs, and a breakdown of the SCR feedback does not occur, the rainfall response to cold IODE SSTAs (pIODs) is greater than for warm SSTAs (nIODs). As such, the positive slope differences seen in Figs. $2 \mathrm{a}$ and $2 \mathrm{~b}$ are associated with more negative IODE SST skewness. Furthermore, the thermocline feedback strengthens under global warming meaning that its influence on SST is greater and thus the precipitation response to SST also increases. This can explain why the relationship between IODE SST skewness and slope difference for the rainfall response to SST becomes stronger under global warming (Fig. 2b). Nevertheless models show large differences in the feedbacks from low level clouds $^{20}$ and the simulation of cloud and convection related processes are a primary cause of model uncertainty ${ }^{21}$.

The Bjerknes feedback over the tropical IO is primarily driven by the thermocline feedback which involves the SST response to thermocline depth anomalies ${ }^{12,19}$. Analysis of the subsurface temperature (at $75 \mathrm{~m}$ depth, T75) response to the thermocline shows an asymmetry, indicating that the thermocline feedback is primarily driven by the ocean (Fig. S1). The other two processes associated with the Bjerknes feedback (the zonal wind response to SST and the thermocline response to zonal wind) do not play a significant role in generating IODE SST skewness (Fig. S2). Models that have a greater zonal wind response to cold IODE SSTAs tend to also display more negative IODE SST skewness (Fig. S2a). However unlike the thermocline feedback (Fig. 2c), this relationship is not significant at the 95\% confidence level.

Due to the mean September-November (SON) winds over the central equatorial IO $\left(70^{\circ} \mathrm{E}-90^{\circ} \mathrm{E}, 5^{\circ} \mathrm{S}-5^{\circ} \mathrm{N}\right)$, the thermocline is climatologically deep in the eastern IO, off the Sumatra-Java coast. As the IOD is dominated by its eastern pole, the thermocline feedback plays an important role in generating IOD skewness ${ }^{11,12,19}$. This depth of the mean IODE thermocline means that it is sensitive to anomalous winds that act to shoal it, which occurs when the mean westerly winds weaken during normal pIOD events, or reverse during extreme events ${ }^{11}$. When this occurs, the thermocline moves closer to the surface, assisting the generation of cold IODE SSTAs. This is a positive feedback that reinforces the generation of pIODs.

Conversely, when the mean westerly winds become stronger, they act to deepen the thermocline in the east, which suppresses colder deep water. However, the deep climatological thermocline is not as sensitive to these westerly wind anomalies and thus, its influence on SST is reduced. This causes the SST response to thermocline depth anomalies to be stronger during pIODs and weaker during nIODs. Most (17) of the 19 CMIP5 models exhibit this asymmetric SST response during the historical SON period (Fig. 2c).

The influence of the thermocline feedback on historical IODE SST skewness can be seen in Fig. 2c. This figure shows that models with a 
a) Hist. precip response to SST

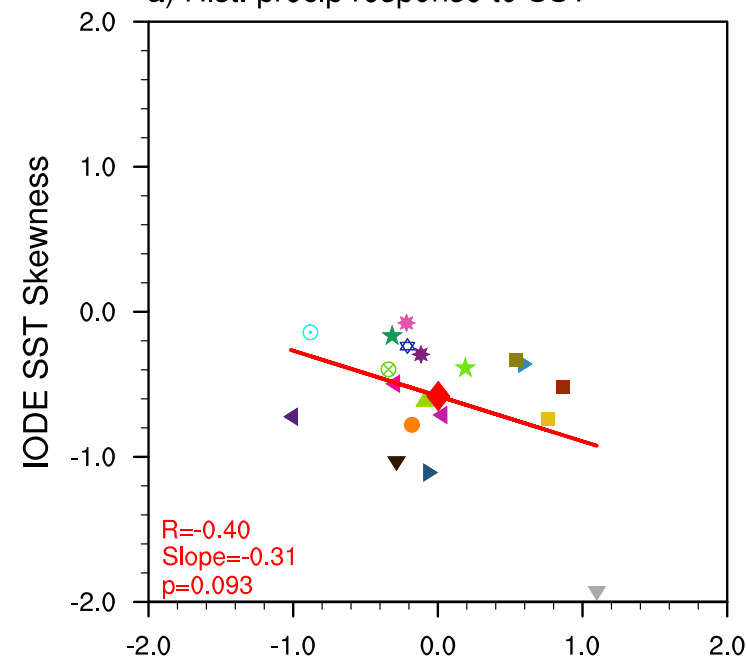

c) Hist. SST response to ZT

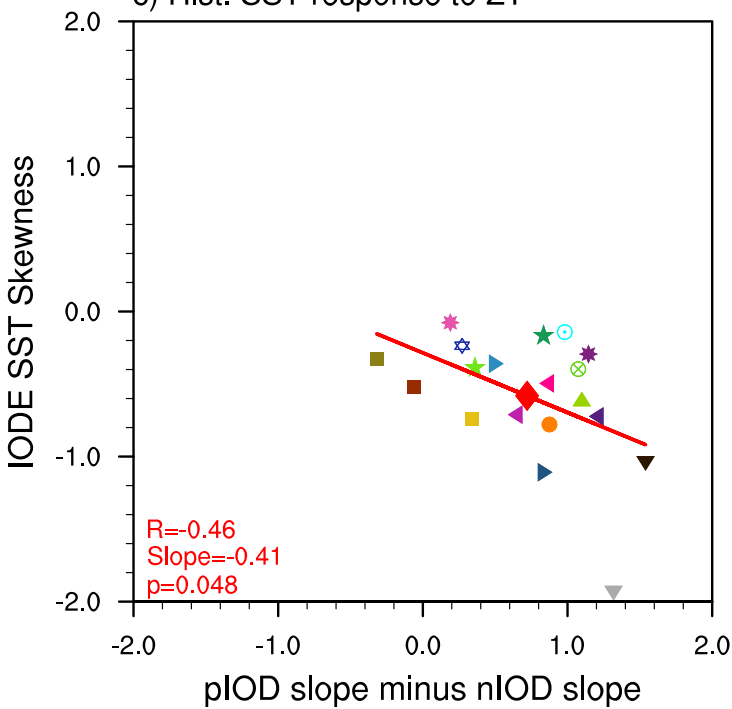

b) RCP8.5 precip response to SST

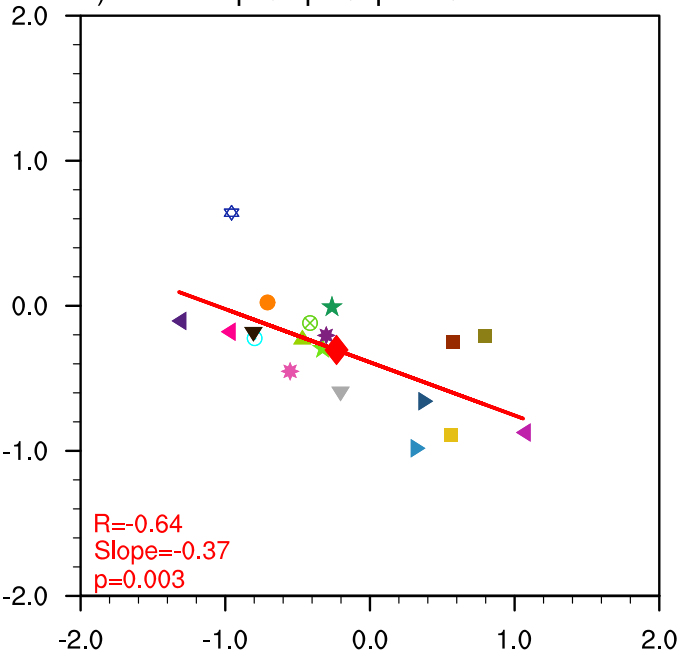

d) RCP8.5 SST response to ZT

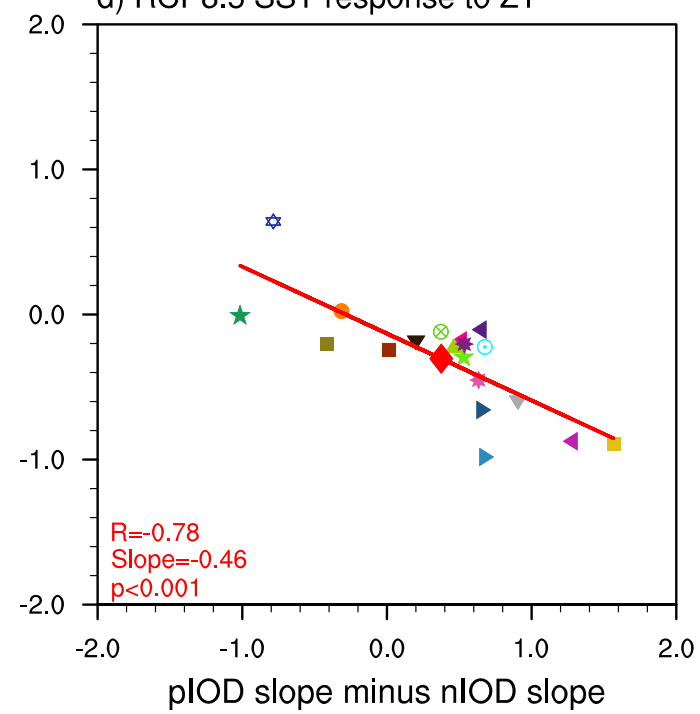

- CanESM2

$\otimes$ CESM1-CAM5

CNRM-CM5

* CSIRO Mk3-6-0

* GISS-E2-H

$\star$ GISS-E2-R

4 GFDL-CM3

4 GFDL-ESM2G

4 GFDL-ESM2M

IPSL-CM5A-LR

- IPSL-CM5A-MR

MIROC5

MIROC-ESM

- MIROC-ESM-CHEM

$\checkmark$ MPI-ESM-LR

$\checkmark$ MPI-ESM-MR

A MRI-CGCM3

* NorESM1-M

* NorESM1-ME

Ensemble mean

Figure $2 \mid$ Relationship between IODE SST skewness and feedback asymmetry. (a) Historical SON IODE SST skewness response to the slope difference for the precipitation response to SSTAs for 19 CMIP5 models. (b) As in (a) but for the RCP8.5 period. (c), (d) As in (a), (b) but for the SST response to thermocline depth $(\mathrm{ZT})$ anomalies. The slope difference is defined as the pIOD linear regression coefficient minus the nIOD linear regression coefficient. These regression coefficients are calculated using analysis similar to that of Fig. 1. All plots were generated in NCL.

positive slope difference, which occurs when the SST response to a shoaling thermocline (i.e., a pIOD) is larger than the response to a deepening thermocline (i.e., a nIOD), tend to have stronger negative IODE SST skewness. This relationship between thermocline feedback asymmetry and IODE SST skewness is significant at the 95\% confidence level using Student's two-tailed $t$-test, suggesting that the skewness is strongly related to the asymmetry of the thermocline feedback.

Under increasing greenhouse gases, the SST skewness response to the slope difference becomes slightly stronger (Fig. 2d). This behaviour indicates that under global warming, the thermocline feedback strengthens and thus it has a stronger influence on SST skewness. Similar to the historical period, the linear correlation coefficient is also significant at the $95 \%$ confidence level. These figures show that the thermocline feedback plays an important role in the modelled SST skewness in both the historical and RCP8.5 periods. However, Fig. 2d does not indicate how the thermocline feedback has changed under global warming, or how this impacts its role in generating IOD skewness. To examine this, the difference between RCP8.5 and historical simulations is plotted for both IODE SST skewness and the slopes of the thermocline feedback (Fig. 3). Most of the models show a negative change in slope difference, indicating that the RCP8.5 slope difference between positive and negative IODs is less than the historical value. For these models, the asymmetry of the thermocline feedback is decreasing. From this, it is clear that there is a strong relationship between IOD skewness and the asymmetry of the thermocline feedback. Figure 3 also shows that the majority of models (14) simulate a weakening in IODE SST skewness in response to global warming. This relationship between the change in skewness and the change in slope difference is significant at the $95 \%$ confidence level.

Why does thermocline feedback asymmetry weaken? From Fig. 3, it can be seen that the asymmetry of the thermocline feedback tends to weaken in the RCP8.5 scenario and here, the causes and mechanisms for this weaker asymmetry will be discussed. The primary hypothesis for this is that as the Earth warms, the Walker circulation is expected to weaken and over the central equatorial IO, leading to a weakening of the SON mean westerly winds ${ }^{12,19,22}$. This allows the climatological thermocline in the eastern IO to shoal, and this behaviour would explain both the weaker asymmetry, as well as the stronger thermocline feedback in the RCP8.5 scenario. 


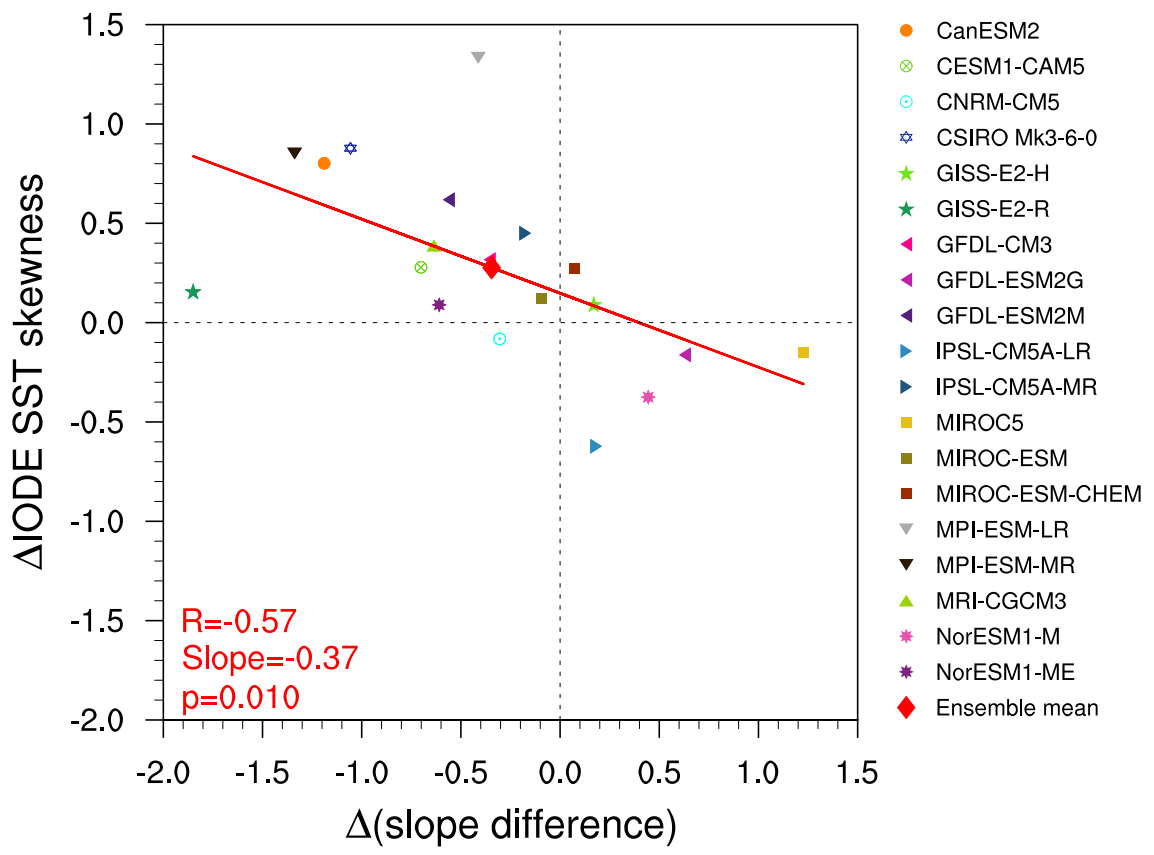

Figure 3 Relationship between change in IODE SST skewness and the change in thermocline feedback asymmetry. SON IODE SST skewness change (RCP8.5 minus historical) versus the change in slope difference (asymmetry) for the thermocline feedback. The slope difference is defined as the pIOD linear regression coefficient minus the nIOD linear regression coefficient. Linear correlation, regression and $p$ values are indicated in the bottom left hand corner. All plots were generated in NCL.

Do the models exhibit this response, where the Walker circulation weakens due to increasing greenhouse gases? Most (18) of the 19 models display this behaviour with the eastern IO warming slower than the west, generating a pIOD-like pattern (Fig. 4a). Only the GFDL-ESM2G model shows an opposite change in SST, with slightly stronger warming over the eastern IO than the west (figure not shown). For the remaining models, this SST pattern leads to weaker westerly winds in RCP8.5 and thus, the difference between RCP8.5 and historical winds is easterly along the central equatorial IO. This leads to a shoaling of the mean IODE thermocline in the models. Figure $4 \mathrm{~b}$ shows the MME mean change in thermocline depth and winds over the tropical IO. Strong shoaling over the IODE region is clear whilst in the western IO, the change due to global warming is much weaker and more varied. The change in precipitation can also be seen in Fig. 4a (contours) and a decrease (increase) in mean precipitation occurs over the eastern (western) IO. This is further evidence that the Walker circulation is weakening in the models, as the decrease in rainfall implies less convection occurring over the IODE region, which is where the rising branch is located. The importance of mean state change is highlighted in Fig. 4c, which shows the relationship between the change in IODE SST skewness and the RCP8.5/historical ratio of mean thermocline depth. The strong correlation implies that differences in skewness change are systematically related to changes in the mean depth of the thermocline. Smaller ratio values, which indicate greater shoaling, are associated with greater positive changes in IODE SST skewness (i.e., larger reductions in skewness).

\section{Discussion}

Using a CMIP5 ensemble and inter-model statistics, it is shown that IOD skewness is primarily driven by the thermocline feedback. This feedback generates IOD asymmetry by reinforcing pIODs more strongly than nIODs, allowing pIOD events to develop larger in amplitude and is the main source of skewness during both the historical and RCP8.5 periods. Whilst previous studies ${ }^{13}$ have suggested that IOD skewness is caused by the negative SCR feedback, this does not occur in the models analysed. Rather, the positive IOD skewness is generated despite greater damping of pIODs than nIODs.

The majority of CMIP5 models in this study show weakening IODE SST skewness in response to global warming and it is clear that there is a significant relationship between the change in thermocline feedback asymmetry, and IODE SST skewness. This is further evidence that IOD skewness is driven by the thermocline feedback. The primary process behind this weakening is a shoaling of the mean eastern IO thermocline, which strengthens the thermocline feedback, but reduces its asymmetry. This is largely driven by a weakening of the IO branch of the Walker circulation, a response that most of the models exhibit.

\section{Methods}

Model data. Historical and RCP $8.5^{23}$ thermocline depth (defined as the depth of the maximum vertical temperature gradient, ZT), zonal wind stress, precipitation, and ocean velocities from 19 CMIP5 $^{24}$ models are used in this analysis. These 19 models were chosen as they are able to realistically simulate both negative IODE SST skewness and positive Dipole Mode Index (DMI) skewness during the historical September-October (SON) season (Table S1), which is when the IOD peaks s. $^{1,2}$ Typically, the strength of the IOD is measured by the $\mathrm{DMI}^{1}$, which is the SSTA difference between the western pole $\left(50^{\circ} \mathrm{E}-70^{\circ} \mathrm{E}, 10^{\circ} \mathrm{S}-10^{\circ} \mathrm{N}\right)$ and the IODE, but as SST variance is larger over the IODE ${ }^{25,26}$, we focus on this region. Decadal and multidecadal variability is significant over the Indian Ocean ${ }^{27}$ and to exclude this variability, a 9 -year running average is removed. The periods analysed span 95 -years each, 1911-2005 and 2006-2100 for the historical and RCP8.5 simulations, respectively. Compared to observations, most CMIP5 models simulate stronger SST variability over the IODE region and the IOD amplitude tends to be larger ${ }^{28}$. The seasonal phase locking of the IOD is well simulated in CMIP5 models ${ }^{29}$.

Statistical analysis. Linear regression and correlation analysis are used to assess the strength of the relationship between variables (e.g., the SST response to thermocline depth anomalies) for separate positive only and negative only samples. This analysis allows the asymmetry of the feedbacks to be examined and from this, the difference in the linear regression (i.e., slope) values can be calculated. The slope difference (i.e., the slope for cool IODE SSTAs (pIODs) minus the slope for warm SSTAs (nIODs)) provides a measure of the asymmetry for the feedbacks and the response of IODE SST skewness to this slope difference can be assessed.

Seasonality. All calculations in this paper are performed over the austral spring season (September-November, SON), which is when the IOD peaks. 


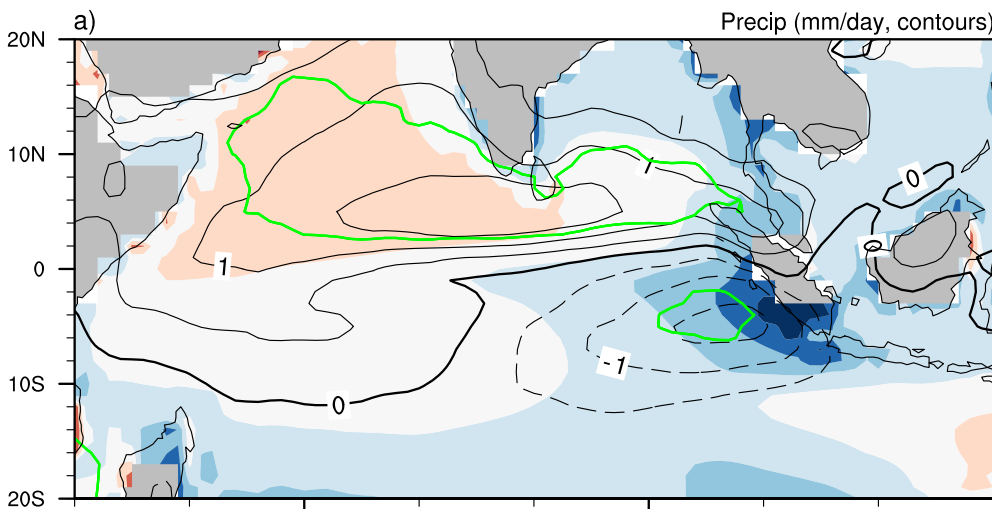
Precip ( $\mathrm{mm} / \mathrm{day}$, contours)

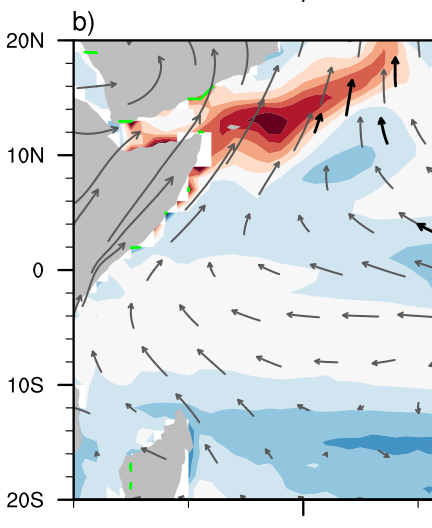

$60 \mathrm{E}$

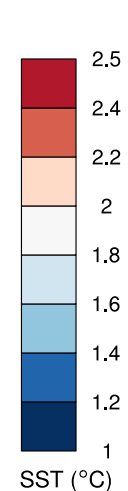

Wind stress $(\mathrm{Pa})$

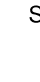

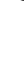

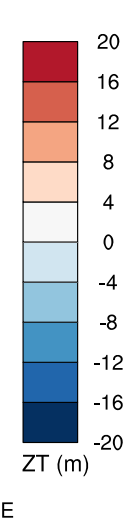

Figure $4 \mid$ Mean state change over the tropical Indian Ocean. (a) Map showing the multi-model ensemble mean SON change (RCP8.5 minus historical) in SST (colours) and precipitation (contours, negative values are dashed). The green contours mark where the change in precipitation is significant at the $95 \%$ confidence level. The change in SST is significant everywhere at the $95 \%$ confidence level. (b) As in (a) but for thermocline depth (ZT, colours) and wind stress (vectors). Black vectors are where the zonal or meridional wind stress change is significant at the $95 \%$ confidence level. The green contours show where the ZT change is significant at the 95\% confidence level. The significance for (a) and (b) is calculated using Student's two tailed $t$-test. (c) Scatter plot showing the relationship between the change in IODE SST skewness (RCP8.5 minus historical) and the ratio of mean thermocline depth for the RCP8.5 and historical simulations. All maps and plots were generated in NCL.

Graphics software. All maps and plots were produced using NCAR Command Language (NCL).

1. Saji, N. H., Goswami, B. N., Vinayachandran, P. N. \& Yamagata, T. A dipole mode in the tropical Indian Ocean. Nature 401, 360-363 (1999).

2. Webster, P. J., Moore, A. M., Loschnigg, J. P. \& Lebel, R. R. Coupled oceanicatmospheric dynamics in the Indian Ocean during 1997-1998. Nature 401, 356-360 (1999).

3. Hong, C.-C., Li, T., Ho, L. \& Kug, J.-S. Asymmetry of the Indian Ocean dipole. Part I: Observational analysis. J. Climate 21, 4834-4848 (2008).

4. Hong, C.-C., Li, T. \& Luo, J.-J. Asymmetry of the Indian Ocean dipole. Part II: Model diagnosis. J. Climate 21, 4849-4858 (2008).

5. Cai, W., van Rensch, P., Cowan, T. \& Hendon, H. H. An asymmetry in the IOD and ENSO teleconnection pathway and its impact on Australian climate. J. Climate 25, 6318-6329 (2012).

6. Ashok, K., Guan, Z. \& Yamagata, T. Influence of the Indian Ocean Dipole on the Australian winter rainfall. Geophys. Res. Lett. 30, 1821 (2003).

7. Black, E., Slingo, J. \& Sperber, K. R. An observational study of the relationship between excessively strong short rains in coastal East Africa and Indian Ocean SST. Mon. Weather Rev. 131, 74-94 (2003).

8. Ummenhofer, C. C. et al. What causes southeast Australia's worst droughts? Geophys. Res. Lett. 36, L04706 (2009).

9. Cai, W., Cowan, T. \& Raupach, M. Positive Indian Ocean Dipole events precondition southeast Australia bushfires. Geophys. Res. Lett. 36, L19710 (2009).

10. Hashizume, M., Chaves, L. F. \& Minakawa, N. Indian Ocean Dipole drives malaria resurgence in East Africa highlands. Sci. Rep. 2, 269 (2012).

11. Cai, W. et al. Projected response of the Indian Ocean Dipole to greenhouse warming. Nat. Geosci. 6, 999-1007 (2013).

12. Zheng, X.-T. et al. Indian Ocean dipole response to global warming in the CMIP5 multimodel ensemble. J. Climate 26, 6067-6080 (2013).

13. Hong, C.-C. \& Li, T. Independence of SST skewness from thermocline feedback in the eastern equatorial Indian Ocean. Geophys. Res. Lett. 37, L11702 (2010).

14. Cai, W. \& Qiu, Y. An observation-based assessment of nonlinear feedback processes associated with the Indian Ocean dipole. J. Climate 26, 2880-2890 (2012).
15. Ogata, T., Xie, S.-P., Lan, J. \& Zheng, X.-T. Importance of ocean dynamics for the skewness of the Indian Ocean dipole mode. J. Climate 26, 2145-2159 (2013).

16. Ng, B., Cai, W. \& Walsh, K. Nonlinear feedbacks associated with the Indian Ocean Dipole and their response to global warming in the GFDL-ESM2M coupled climate model. J. Climate (In press).

17. Carton, J. A. \& Giese, B. S. A Reanalysis of Ocean Climate Using Simple Ocean Data Assimilation (SODA). Mon. Weather Rev. 136, 2999-3017 (2008).

18. Rayner, N. A. et al. Global analyses of sea surface temperature, sea ice, and night marine air temperature since the late nineteenth century. J. Geophys. Res. 108, 4407 (2003).

19. Zheng, X.-T., Xie, S.-P., Vecchi, G. A., Liu, Q. \& Hafner, J. Indian Ocean dipole response to global warming: Analysis of ocean-atmospheric feedbacks in a coupled model. J. Climate 23, 1240-1253 (2010).

20. Sherwood, S. C., Bony, S. \& Dufresne, J.-L. Spread in model climate sensitivity traced to atmospheric convective mixing. Nature 505, 37-42 (2014).

21. Sherwood, S. C. et al. Climate Processes: Clouds, Aerosols and Dynamics in Climate Science for Serving Society (eds Asrar, G. R. \& Hurrell, J. W.) Ch. 4, 73-103 (Springer Netherlands, 2013).

22. Vecchi, G. A. \& Soden, B. J. Global Warming and the Weakening of the Tropical Circulation. J. Climate 20, 4316-4340 (2006).

23. Moss, R. H. et al. The next generation of scenarios for climate change research and assessment. Nature 463, 747-756 (2010).

24. Taylor, K. E., Stouffer, R. J. \& Meehl, G. A. An overview of CMIP5 and the experimental design. Bull. Amer. Met. Soc. 93, 485-498 (2012).

25. Saji, N. H. \& Yamagata, T. Structure of SST and surface wind variability during Indian Ocean dipole mode events: COADS observations. J. Climate 16, 2735-2751 (2003).

26. Hong, C.-C., Lu, M.-M. \& Kanamitsu, M. Temporal and spatial characteristics of positive and negative Indian Ocean dipole with and without ENSO. J. Geophys. Res. 113, D08107 (2008).

27. Deser, C., Phillips, A. S. \& Hurrell, J. W. Pacific interdecadal climate variability: Linkages between the tropics and the north Pacific during boreal winter since 1900. J. Climate 17, 3109-3124 (2004).

28. Weller, E. \& Cai, W. Realism of the Indian Ocean Dipole in CMIP5 Models: The Implications for Climate Projections. J. Climate 26, 6649-6659 (2013). 
29. Liu, L. et al. Indian Ocean variability in the CMIP5 multi-model ensemble: the zonal dipole mode. Climate Dyn. (In press).

\section{Acknowledgments}

We thank the modelling groups for making their model output available. We also thank Evan Weller and Tim Cowan for their suggested improvements. This work is supported by the CSIRO Wealth from Oceans Flagship.

\section{Author contributions}

B.N. and W.C. designed the research. B.N. conducted the analysis and wrote the initial draft. W.C. and K.W. contributed to the interpretation of the results and reviewed the manuscript.

\section{Additional information}

Supplementary information accompanies this paper at http://www.nature.com/ scientificreports

Competing financial interests: The authors declare no competing financial interests. How to cite this article: Ng, B., Cai, W. \& Walsh, K. The role of the SST-thermocline relationship in Indian Ocean Dipole skewness and its response to global warming. Sci. Rep. 4, 6034; DOI:10.1038/srep06034 (2014).

cc)(1) This work is licensed under a Creative Commons Attribution-NonCommercialShareAlike 4.0 International License. The images or other third party material in this article are included in the article's Creative Commons license, unless indicated otherwise in the credit line; if the material is not included under the Creative Commons license, users will need to obtain permission from the license holder in order to reproduce the material. To view a copy of this license, visit http:// creativecommons.org/licenses/by-nc-sa/4.0/ 